\title{
Pesticide and agro-ecological transition: assessing the environmental and human impacts of pesticides and limiting their use
}

\author{
Marc Voltz ${ }^{1}$ - Gilles Guibaud ${ }^{2}$. Cécile Dagès ${ }^{1} \cdot$ Jean-Paul Douzals ${ }^{3} \cdot$ Robin Guibal $^{2}$ - Sonia Grimbuhler ${ }^{3}$. \\ Olivier Grünberger ${ }^{1} \cdot$ Sophie Lissalde ${ }^{2} \cdot$ Nicolas Mazella $^{4} \cdot$ Anatja Samouëlian $^{1} \cdot$ Stéphane Simon $^{2}$
}

Published online: 18 November 2021

(c) The Author(s), under exclusive licence to Springer-Verlag GmbH Germany, part of Springer Nature 2021

This special issue of Environmental Science and Pollution Research gathers selected papers presented at the $48^{\text {th }}$ and $49^{\text {th }}$ congresses of the French pesticide research group (Groupe Français de recherches sur les Pesticides, GFP) that took place in May 2018 and May 2019 in Limoges and Montpellier, France, respectively. The congresses of GFP review the knowledge acquired by the French-speaking scientific community in all areas relating to pesticides. This includes their effectiveness, modes of action and fate in the different compartments of ecosystems, the remediation processes, the metrology and monitoring approaches, the methods of diagnosis and modelling of contamination and impacts. The GFP congresses are an opportunity to crossfertilise expertise in various disciplinary fields: analytical developments, toxicological and ecotoxicological impacts of pesticides, fate of compounds into the environment, curative and alternative solutions.

The $48^{\text {th }}$ edition focused on "Pesticide metrology and risk assessment for humans and the natural environment" with highlights on headwaters contamination with

Responsible Editor: Philippe Garrigues

Marc Voltz

marc.voltz@inrae.fr

1 Unité Mixte de Recherche sur les Interactions Sols-Agrosystèmes-Hydrosystèmes (LISAH), Université de Montpellier, INRAE, IRD, Institut Agro, 2 place Viala, 34060 Cedex 1 Montpellier, France

2 Peirene-Eau, EA 7500-URA INRAE, Université de Limoges, 123 Avenue Albert Thomas, 87 060m, Limoges Cedex, France

3 Unité Mixte de Recherche sur les Technologies \& Méthodes pour les Agricultures de Demain (ITAP), Université de Montpellier, INRAE, Institut Agro, 361 rue Jean - François Breton BP 5095, 34196 Montpellier, France

4 Centre de Bordeaux, INRAE, UR EABX - Équipe ECOVEA, 50 avenue de Verdun, 33612 Cestas cedex, France pesticides and their by-products the third day of the congress. Other aspects of research about pesticides were also presented and discussed including metrology and analytical methods for monitoring pesticides, pesticides and human health: exposure of users and consumers, pesticides and networks (rainwater, drinking water and wastewater), alternative methods and agro-ecology, impacts on ecosystems: chronic/acute toxicity, passive/active exposure, pesticides, environmental law and environmental policy (national, European) and societal perceptions of pesticide-related issues. About forty oral presentations and eight poster presentations were given during three days with more than 120 participants. During the $48^{\text {th }}$ Congress, special attention was paid to the transfer of scientific advances to actors on the ground, but also to the general public. Thus, a full day of the congress was dedicated to various conferences presenting different aspects on the trend of pesticides in an urban environment or in the headwaters context with passionate debates around the interest of regulating the research about particular herbicides by-products. The $48^{\text {th }}$ GFP congress ended with a series of conferences given by members of the laboratory of the University of Limoges and the NGO OIEau (www.oieau.fr) to provide objective and factual information to the general public. The debate in France in 2018 about the effect of glyphosate and neonicotinoids on humans or on bees, respectively, was important between all stakeholders. This series of conferences was an opportunity to discuss with actors on the field and the general public with scientific bases. This allowed each participant to make its own opinion on the interest of the use of phytosanitary products allowing a clear progress in agriculture in order to ensure food production for a growing world population and an increasingly highlighted health and environmental impact.

The $49^{\text {th }}$ congress in Montpellier focused on the theme "Pesticides and agro-ecological transition: challenges and progress", with particular attention to the countries 
of the Mediterranean basin. Indeed, the use of pesticides in agriculture and their impact on the environment and human health is a subject that has been regularly addressed for many years in the public and political debate in France. In 2008, a phase of consultation (Grenelle de l'Environnement) of state and local authorities, trade unions, NGOs and public led to the objective of reducing the use of these products by $50 \%$ in France. After more than a decade, it is clear that this objective has not been achieved despite the efforts made. In link with this aim of reducing pesticide use, research activities have evolved as could be seen in the 82 oral and poster presentations at the $49^{\text {th }}$ GFP congress. The papers presented indicate a strengthening of the work on improving our understanding and reducing the use of pesticides, and on the impacts of spraying on both biological organisms and landscapes. In particular, it highlighted a significant potential for reducing the quantities of pesticides applied without reducing the effectiveness of plant protection by using more efficient application tools that limit the drift phenomenon as much as possible. The decisive influence of sociological factors and training on the use of pesticides was illustrated in several papers. In terms of diagnosing environmental contamination by pesticides, the congress showed that all matrices-soil, water, air, plants and animals-are now being studied. This is a step towards a more systemic and comprehensive study of the impacts of pesticide use. The presentation of new pesticide analysis techniques based on high-resolution mass spectrometry detection favours this evolution since these techniques allow the search for a greater number of molecules in the samples studied. The work presented on the impacts on human health was diversified, ranging from studies on the exposure of the general population to that of applicators and people living near spraying operations, but also to the study of the physiological mechanisms induced by exposure. Finally, we underline the emergence of numerous works for the observation and modelling of the influence of the organisation and management of cultivated landscapes on the dispersion of pesticides and their ecotoxicological impacts. This marked extension of the spatial scale of study of the fate of pesticides in the environment answers the objective of better understanding the pollution pressures exerted on biological populations, but also answers the aim of searching levers for the agroecological management of cultivated ecosystems that enhance biodiversity.

Amongst all presentations made at the two congresses, this special issue gathers 5 papers. They represent only a small part of the subjects discussed at the two congresses, but illustrate the major concerns about the understanding and monitoring of the contamination by pesticides of ecosystem compartments.
A main challenge in the management of water pollution at the catchment level is to identify vulnerability zones where priority actions should be taken to limit the pollution risks. The methodologies for mapping these zones are constantly improving thanks to the development of higher-resolution data bases including a wider range of geographic, agricultural and hydrological data and to improved spatial analysis and mapping procedures. Grimene et al. (2021) present a recently developed mapping methodology of vulnerability zones to pesticide pollution that considers 11 vulnerability factors of agricultural or pedoclimatic origin. They illustrate their methodology on the case of the 820 $\mathrm{km}^{2}$ Gimone watershed where $70 \%$ of land use is intensive cropland.

Another important issue in water pollution management is the ability to monitor water quality over networks of sampling spots. Current monitoring procedure of surface waters still rely on low frequency grab sampling, which does not ensure unbiased estimation of either average or peak pollution levels. Passive samplers have been developed to offer an integrative measurement capacity of several weeks. However, as stressed by Bernard et al. (2018), there is little experience about whether passive sampler can also catch peak contamination events. Bernard et al. (2018) therefore evaluated in a lab experiment the capacity of the Polar Organic Chemical Integrative Samplers (POCIS) to record such events for a range of pesticides with different polarities.

The environmental fate of chlordecone, a very persistent organochlorine massively applied in the banana fields of the French West Indies between 1972 and 1993, is still a major concern for French environmental researchers as it contaminated severely the terrestrial and marine ecosystems of these Caribbean islands,. Two papers in this special issue investigate some of the processes that lead to the contamination of coastal ecosystems by means of chlordecone runoff from the contaminated watersheds. In one paper, Dromard et al. (2019) examined the consistency of three hypothesis: (i) chlordecone can stay sorbed on the volcanic soils particles during their transfer from contaminated soils to the marine environment, (ii) zooplankton can represent a major pathway of chlordecone to the trophic marine food chain, (iii) chlordecone concentrates in marine organisms, depending on their proximity to the source of chlordecone and their feeding ecology. To this aim, Dromard et al. (2019) combined a desorption study of chlordecone in saline water from allophanes, a major amorphous mineral of the volcanic soils, and the measurement of contamination of the trophic food chain in mangroves, seagrass beds and coral reefs. In the other paper, Devault et al. (2021) investigated the processes of contamination and decontamination by chlordecone and arsenic of Sargassum sp. that accumulates regularly on the Caribbean beaches since 2011 
and causes severe nuisance. Indeed, possible contamination of these algae on the beaches has to be considered in their treatment plans. Therefore, Devault et al. (2021) performed in situ and mesocosm experiments to analyse the specific kinetics of adsorption and desorption of both compounds to Sargassum sp. in coastal conditions.

A last concern highlighted in this special issue is the contamination of untreated fields and areas by pesticides. Devault et al. (2019) examine the possible ways of dispersion of prosulfocarb, a dithiocarbamate that is increasingly used as a pre-emergence herbicide given the ban of some herbicides and developing bioresistance of weeds to others. They review published and official data on Prosulfocarb physico-chemical properties and on its detection in various media to discuss the risks of Prosulfocarb in contaminating untargeted environmental compartments.

Acknowledgements We would like to thank all partners that provided financial and human support to the organisation of the $48^{\text {th }}$ and $49^{\text {th }}$ GFP congresses, namely, Région Nouvelle Aquitaine, Ville de Limoges, Université de Limoges, Aquatech-Limoges, CIL-Cluzeau Info Labo, Agilent Technologies, Shimadzu, ThermoFicher Scientific, CEM, for the $48^{\text {th }}$ congress and Région Occitanie, INRAE, IRD, Key Initiatives Waters et Vine \& Wine Sciences of Montpellier University of Excellence, Institut National Universitaire Champollion d'Albi, CEM SAS, CIL Cluzeau Info Labo, Thermo Fisher Scientific for the $49^{\text {th }}$ congress.

\section{References}

Bernard M, Boutry S, Tapie N et al (2018) Lab-scale investigation of the ability of Polar Organic Chemical Integrative Sampler to catch short pesticide contamination peaks. Environ Sci Pollut Res. https://doi.org/10.1007/s11356-018-3391-2

Devault DA, Guillemin JP, Millet M et al (2019) Prosulfocarb at center stage! Environ Sci Pollut Res. https://doi.org/10.1007/ s11356-019-06928-8

Devault DA, Massat F, Baylet A et al (2021) Arsenic and chlordecone contamination and decontamination toxicokinetics in Sargassum sp. Environ Sci Pollut Res. https://doi.org/10.1007/ s11356-020-12127-7

Dromard CR, Devault DA, Bouchon-Navaro Y et al (2019) Environmental fate of chlordecone in coastal habitats: recent studies conducted in Guadeloupe and Martinique (Lesser Antilles). Environ Sci Pollut Res. https://doi.org/10.1007/s11356-019-04661-w

Grimene C, Mghirbi O, Louvet S et al (2021) Spatial characterization of surface water vulnerability to diffuse pollution related to pesticide contamination: case of the Gimone watershed in France. Environ Sci Pollut Res. https://doi.org/10.1007/s11356-021-14253-2

Publisher's note Springer Nature remains neutral with regard to jurisdictional claims in published maps and institutional affiliations.

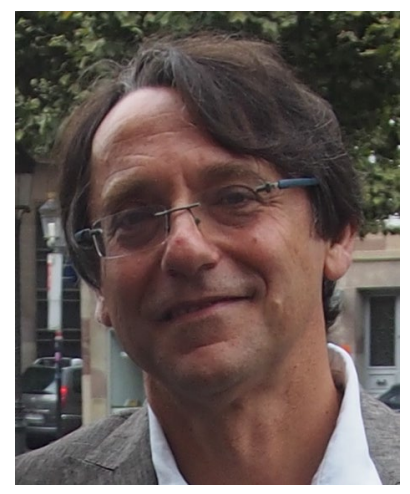

Marc Voltz, is research director at INRAE (formerly INRA) and adjunct Professor at the School of Agronomy in Montpellier (SupAgro Montpellier). He joined INRA in 1982 and completed a $\mathrm{PhD}$ in Soil Science and Soil Physics in 1986. His main topics of research concern water and pollutant transport processes in soils, soil water balance modelling, catchment hydrology, distributed hydrological modelling, soil mapping methods including geostatistical techniques. He used to be Head of the INRA-

IRD-SupAgro joint research unit on the interactions between soil, agriculture and hydrology (LISAH) from 2003 to 2010. He currently coordinates a multidisciplinary project for developing an integrated model of pesticide fate at the landscape scale including atmospheric and hydrological transfer processes after spraying.

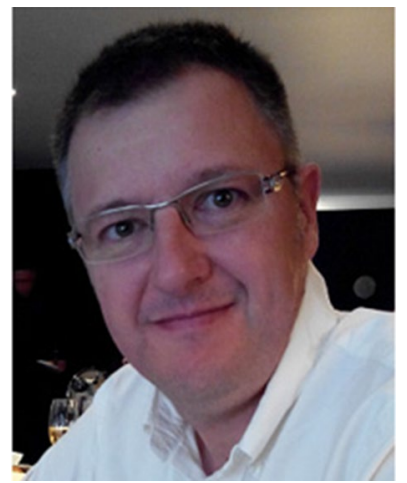

Gilles Guibaud, is Professor at the University of Limoges. He joined University of Limoges in 1988 and completed a $\mathrm{PhD}$ in Chemistry and microbiology of water in 1996 and an habilitation thesis in 2003. His main topics of research concern water quality in accordance with human use or for aquatic environment ability targeting organic and mineral micropollutants. To monitor water quality at watershed scale, passive sampling approach was performed. He currently manhuman impact in the headwaters area. ages projects for evaluating

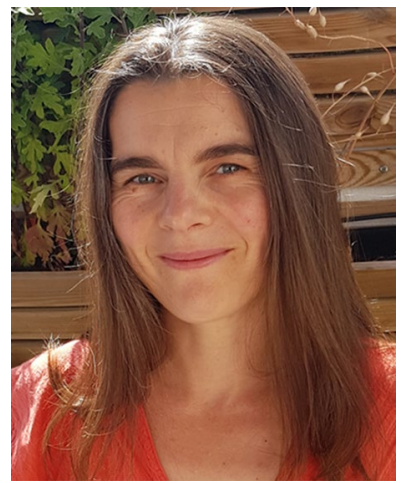

Cécile Dagès, is a scientist at INRAE in the LISAH Joint Research Unit since 2007. Her research mainly focuses on the modeling of the fate of pesticides in agricultural landscapes, with a particular focus on the effect of agro-ecological infrastructures on both water and pesticide flows. Her study context concerns mainly Mediterranean viticulture. She is currently very involved in the development of integrated modeling approaches of pesticide fate in landscapes that explicitly take into account reactive transfer in ditch networks. She mobilizes these modeling approaches in collaborative projects to explore land use and management scenarios aiming to define sustainable strategies for reducing the impact of pesticides at the landscape scale. 


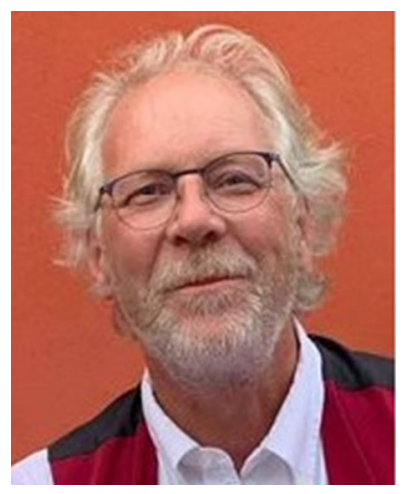

Jean-Paul Douzals, is the head of the Spray Application Research Group at UMR ITAP INRAE Montpellier since 2009 (formely Cemagref then IRSTEA). He graduated in Agricultural Sciences with a specialization in Agricultural Engineering followed by a $\mathrm{PhD}$ in Food Processing Sciences in 1999. His main research activities concern experimental developments for the comprehension of the spray application for plant protection and the definition of performance criteria for the optimization of the process. Expected outcomes are the reduction of plant protection products doses, the definition of satisfying conditions for the development of bioproducts and biocontrol, the reduction of the impacts of spray applications such as spray drift. He is collaborating to several projects with LISAH and ECOSYS research teams aiming at developing an integrated model of PPP transfer in the environment.

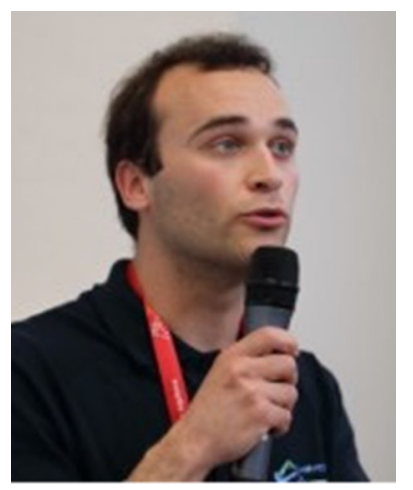

Robin Guibal, is assistant professor at the University of Limoges. He joined University of Limoges in 2011 and completed a PhD in water, soil and environment in 2018. His main topic of research concerns water chemical quality at watershed scale with the target of developing or improving passive sampling approaches for micropollutants (pesticides, pharmaceuticals). This approach is combined to high-resolution mass spectrometry analysis.

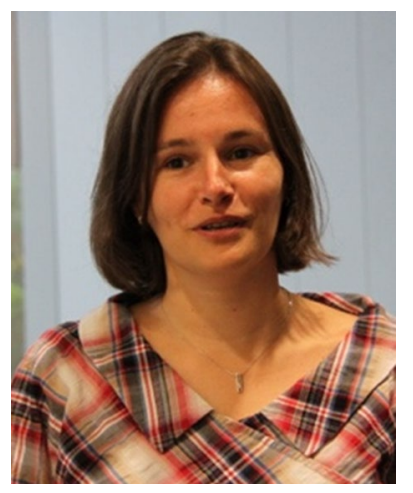

Sonia Grimbuhler, is a researcher in chemistry and toxicology, she is specialized in occupational health in the exposure to pesticides of agricultural workers and local residents. Former PhD student at the EHESP (named ENSP at that time), she holds a researcher position in exposure sciences at the French National Research Institute for Agriculture and the Environment (INRAE). Her work on plant protection products contributes to improve knowledge on farmers' exposure levels, to characterize the influence of physiological parameters on occupational exposures and to model the exposures of operators, workers, local residents and bystanders. She contributed to different research projects (Ecophyto ANSES, ...) and coordinated 8 research projects. In 2020 she was seconded to IRSET. She is an expert for ANSES on the expology part, and also for ministries.

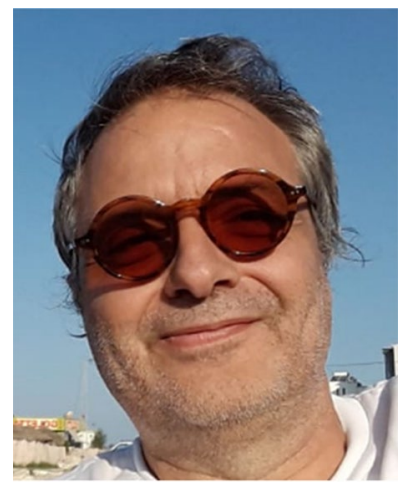

Olivier Grünberger, is a hydrogeochemist researcher specialized in water and soils solutes dynamics and agricultural pollutants contamination processes. He obtained a PhD in earth sciences from Paris X University in 1989 studying underground recharge processes using isotopic and geochemical tracers in $\mathrm{La}$ Réunion Island. $\mathrm{He}$ has been working for the French National Institute of Research for Sustainable Development (IRD) since 30 years, achieving in Mexico and Thailand cooperation programs dealing with soil salinity issues. He obtained a postdoctoral "Habilitation à Diriger des Recherches" from Montpellier University in 2015. Deputy-director of the joint Laboratory of Interactions Soils Hydrosystems and Agrosystems (LISAH) (2010-2020) he co-managed the long term observatory site (OMERE) in Cap Bon peninsula, Tunisia (2016-2021). Presently, he studies pesticide contamination processes in rain-fed and irrigated fields in southern Mediterranean countries and in a French Caribbean Island (Guadeloupe).

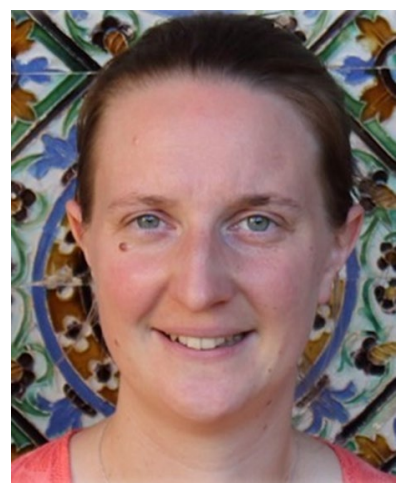

Sophie Lissalde, is research engineer. She joined University of Limoges in 2011, she works in analytical chemistry. Her current research activities include passive sampling development for environmental monitoring, development of analytical methods to quantitate micropollutants, and suspect screening analysis and its application in the natural environment.

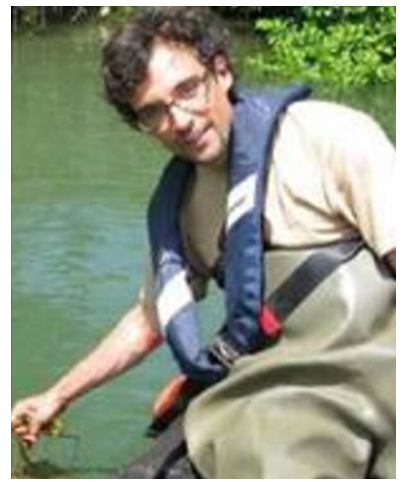

Nicolas Mazella, was recruited as a research engineer at INRAE (formerly Irstea) of Bordeaux, in the "Aquatic Ecosystems and Global Changes" (EABX) Research Unit, since 2007. He is responsible for the water chemistry lab, a part of the EABX research unit. His lines of research include analytical and environmental chemistry, with works particularly relating to the development of passive sampling 
techniques (especially POCIS) so as to better understand pesticide contamination of aquatic environments, and the relationship between exposure/impact on freshwater biofilms in collaboration with hydrobiologists and ecotoxicologists.

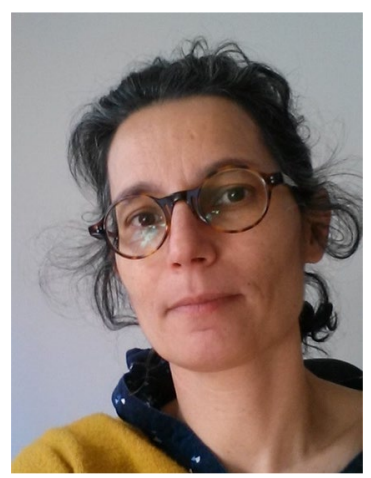

Anatja Samouëlian, has been working as a researcher at the LISAH joint research unit since 2011. She is currently in charge of the Water and Soil Contamination team, which works on the fate of pesticides in cultivated environments in relation to agricultural practices and agroecological infrastructure. More specifically, her research concerns the diagnosis and evaluation of soil and water contamination risks, with a focus on the tropical agropedoclimatic system. In this respect, she participated in the ANSES programme for the development of procedures for the assessment of the risk of pesticide transfer in West Indies soils. She is also actively involved in the OPALE observatory dedicated to pesticide transfers at the catchment scale in French West Indies.

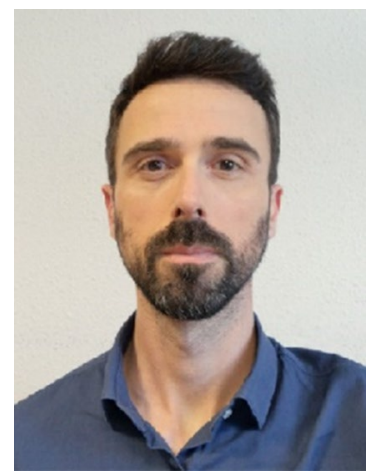

Stéphane Simon, obtained a PhD in analytical chemistry in 2003 and joined the University of Limoges in 2004 as assistant professor. His main topic of research focuses on the development and application of analytical tools for speciation analysis in natural environments and in treatment processes. These analytical tools include hyphenated techniques and passive sampling. 